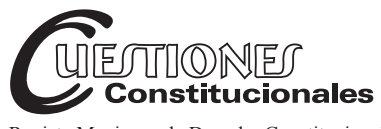

Revista Mexicana de Derecho Constitucional Núm. 43, julio-diciembre 2020

\title{
El olvido previo a Internet: los orígenes del actual derecho al olvido digital*
}

\author{
Forget Before Internet: the Origins of the Right \\ to be Forgotten
}

Ángela Moreno BoBADILLA**

RESUMEN: El derecho al olvido digital se ha convertido en cuestión de capital importancia, debido a la ausencia de fronteras espaciales y temporales propias de Internet. Para poder comprender todo lo relacionado con este derecho emergente, es necesario analizar cuál es su verdadero origen, que es previo a la era digital. La principal finalidad que tiene llevar a cabo este background es tener un conocimiento más profundo y exhaustivo de sus orígenes, que se remontan a finales del siglo XIX, y que se encuentran, principalmente, en Estados Unidos y en Francia.

Palabras clave: derecho al olvido, intimidad, privacidad, protección de datos personales, common law, sistemas civilistas, derechos digitales.
ABSTRACT: The right to be forgotten has become a matter of capital importance, due to the absence of spatial and temporal borders of the Internet. In order to understand everything related to this emerging right, it is necessary to analyze what is its true origin, which is prior to the digital age. The main purpose of carrying out this background is to have a deeper and more exhaustive knowledge of its origins that go back to the end of the 19th century, and which are mainly found in the United States and France.

Keywords: the right to be forgotten, privacy, data protection, common law, civil systems, digital rights.

* Artículo financiado por el Proyecto Fondecyt Iniciación 11180172 “Aspectos fundamentales para la configuración y el desarrollo del derecho al olvido digital en Chile".

** Directora de posgrados de la Facultad de Derecho de la Universidad Andrés Bello, y profesora de Derecho Constitucional de la Facultad de Derecho de la Universidad Andrés Bello. Chile. ORCID: 0000-0003-0828-7459. Correo electrónico: angela.moreno@ unab.cl. 
SUMARIO: I. Introducción. II. Estados Unidos: olvido en el pasado, recuerdo en el presente. III. La primacía de la privacidad en Europa. IV. Conclusiones. V. Bibliografía.

\section{INTRODUCCIÓN}

Desde la antigüedad, el ser humano ha necesitado perdón y rendición. Ha reclamado por tener derecho a una segunda oportunidad. Esta necesidad de volver a comenzar, a pesar de que parece un debate propio de la actualidad, en realidad es anterior a la creación de Internet. ${ }^{1}$

Concretamente, sus orígenes se remontan a finales del siglo XIX y principios del siglo XX, cuando los ciudadanos comienzan a clamar por mantener su vida privada alejada de miradas indiscretas. En palabras de María Álvarez Caro: "El derecho al olvido encuentra sus raíces en el derecho a la intimidad (the right to privacy en su denominación en inglés) y en el derecho a la protección de datos personales, pudiendo considerarse que el derecho al olvido deriva de ellos". ${ }^{2}$

No obstante, antes de la creación de Internet, la memoria humana imperaba sobre la memoria virtual, provocando que el mero transcurso del tiempo convirtiera ciertos datos en irrelevantes.

Sin embargo, en la actualidad este debate ha cobrado una gran relevancia, debido a la inmediatez y la ausencia de fronteras espaciales y temporales, que hacen que cualquier dato del pasado pueda volver al presente. Esto ha provocado que se abra con fuerza el debate relativo al derecho al olvido digital, es decir, a si cada vez que alguien teclee nuestro nombre y apellidos en un buscador puede o debe aparecer cualquier información relacionada con nuestro pasado. ${ }^{3}$

1 González Fuster, Gloria, The Emergence of Personal Data Protection as a Fundamental Right of the EU, Suiza, Springer, 2014, p. 22.

2 Álvarez Caro, María, Derecho al olvido en Internet: el nuevo paradigma de la privacidad en la era digital, Madrid, Reus, 2015, p. 27.

3 De Terwangne, Cecile, "Privacidad en Internet y el derecho a ser olvido/al olvido", Revista de Internet, Derecho y Política, núm. 13, febrero, 2012, pp. 53-66, disponible en: http://doi.org/10.7238/idp.v0i13.1400.

La autora explica las tres facetas que tiene el derecho al olvido, entre las que menciona el derecho al olvido al pasado judicial, el derecho al olvido establecido en la legislación de la protección de datos y el derecho al olvido como equivalente a atribuir una fecha 
Con objeto de poder comprender todo lo relacionado con este derecho emergente, es necesario analizar cuál es el verdadero origen del derecho al olvido, que es previo a la era digital. La principal finalidad que tiene llevar a cabo este background es tener un conocimiento más profundo y exhaustivo de sus orígenes, que se remontan a finales del siglo XIX.

Para ello, el artículo desarrolla un estudio comparado, en donde se parte examinando la evolución que ha habido en esta materia en Estados Unidos, por ser este el país donde nació uno de los derechos con los que guarda una mayor relación: el derecho a la privacidad. A continuación, se estudia su evolución en el continente europeo, que en la actualidad es el punto que tiene un mayor desarrollo en esta cuestión. Concretamente, se analiza el caso de Francia, donde se encuentran los primeros supuestos que siembran los orígenes del derecho al olvido.

Dos visiones muy diferentes, debido a que su germen, la privacidad, en los sistemas del common law, principalmente en Estados Unidos, se basa en la libertad de los individuos para decidir, mientras que en los países de tradición civilista, como España, Alemania, Francia o Italia, entre otros, está basada en la idea de dignidad. ${ }^{4}$

\section{ESTADOS UNIDOS: OLVIDO EN EL PASADO, RECUERDO EN EL PRESENTE}

En el país que se ha convertido en la cuna de la tecnología mundial, se encuentran algunos de los hitos jurisprudenciales más determinantes en materia de derecho al olvido, y que están directamente relacionados con dos momentos que marcaron el inicio del actual debate: el artículo de los

de caducidad a los datos personales, pero que es solamente aplicable al contexto de las redes sociales.

4 Werro, Franz, "The Right to Inform v. the Right to be Forgotten: a Transatlantic Clash", Georgetown University. Center for Transnational Legal Studies Colloquium, núm. 2, 2009, p. 286: "The two Western cultures seem on irreconcilable paths when it comes to the recognition and enforcement of a right to be forgotten". Whitman, James Q., "The Two Western Cultures of Privacy: Dignity Versus Liberty", Yale Law Journal, vol. 113, 2017, disponible en: file://D:/DERECHO\%20AL\%20OLVIDO/UF/OLVIDO\%20 Y\%20PRIVACIDAD/ARTÍCULOS/WHITMAN.pdf, p. 1161: "Continental privacy protections are, at their core, a form of protection of a right to respect and personal dignity... By contrast, America, in this as in so many things, is much more oriented toward values of liberty against the state". 
académicos Samuel Warren y Louis Brandeis y la creación de la teoría de los cuatro torts de William Prosser.

El estudio de estos hitos va a poner en evidencia la cambiante postura de Estados Unidos en esta materia, y que ayuda a comprender el posicionamiento jurídico que hay en la actualidad respecto del derecho al olvido digital en este país. Si bien durante finales del siglo XIX y las primeras décadas del siglo XX la jurisprudencia daba una mayor y acertada preeminencia al derecho a la intimidad de los ciudadanos, llegando a convertirse en un ejemplo para los tribunales europeos, la Corte Suprema cambió el rumbo a finales de los años sesenta, y dio un injustificado valor, prácticamente absoluto, al derecho a la información. Como resultado, hoy en día no hay ni olvido ni perdón en el país norteamericano, sin importar las informaciones protagonizadas por menores, por aquellas personas que han sido protagonistas involuntarias de una noticia, dígase, por ejemplo, una mujer que ha sido víctima de violencia de género, y un sinfín de casos en los que la privacidad de los ciudadanos se ha visto perdida para siempre.

\section{Finales del siglo XIX: the right to privacy}

Hasta 1890 la privacidad en Estados Unidos era concebida como un derecho intangible de propiedad, pero a raíz del célebre artículo "The Right to Privacy", publicado en la Harvard Law Review, ${ }^{5}$ comienza a forjarse la tesis de que cada persona debe tener un reducto de intimidad que sea inaccesible para los demás, siempre y cuando no haya interés público o consentimiento por parte de la persona afectada. ${ }^{6}$

A pesar de que marcó un antes y un después, este artículo ha sido criticado por una parte de la doctrina norteamericana, al afirmar que en realidad lo único que hicieron estos autores fue trasplantar la idea de privacidad que se estaba comenzando a desarrollar en la Europa continental, concretamente en Alemania.

5 Warren y Brandeis sientan las bases de un verdadero derecho a la intimidad, ya que muestran al mundo una nueva concepción respecto de su significación jurídica y social. Su artículo es uno de los más citados de la literatura jurídica a nivel mundial.

6 Moreno Bobadilla, Ángela, Intimidad y menores, Madrid, Centro de Estudios Políticos y Constitucionales, 2017, p. 86. 
En palabras de Schwartz y Peifer:

Their intention seems to have been to draw on continental philosophy to suggest that each person deserves protection against certain kinds of mental harms simply as a consequence of her status as a human. Precisely this idea proved to be highly influential in German law as well as European human rights jurisprudence. ${ }^{7}$

En realidad, este artículo sirvió para que los tribunales estadounidenses comenzaran a ver este derecho como susceptible de protección, y que de forma inconsciente se comenzara a hablar de que la privacidad está relacionada con el derecho al olvido, o sea, con el derecho a tener una segunda oportunidad, haciendo que ciertas informaciones que pertenecen al pasado, y que ya no tienen interés público en el presente, vuelvan a la esfera de la intimidad. ${ }^{8}$

Es relevante resaltar la importancia de estos dos visionarios del derecho, que no solamente elevaron la privacidad a la categoría de derecho, sino que además y gracias a su estudio, determinaron que su importancia radicaba en que su contenido era intangible, alejándolo del derecho de propiedad. Una acertada postura, más cercana al derecho continental que al common law.

Pocos años después de su publicación, se dictó en California la primera ley en materia de privacidad, concretamente en 1899, relativa a la publicación de retratos sin consentimiento, aunque desafortunadamente no tuvo ninguna aplicación práctica, y fue derogada en 1915.

En el ámbito de la jurisprudencia, uno de los primeros casos es el de Robertson v. Rochester Felding Box Co. de 1902, en donde la demandante solicitó el retiro de un anuncio publicitario de una marca de harina que usaba su imagen. A pesar de que la sentencia le fue adversa, se creó un

7 Schwartz, Paul M. y Piefer, Karl-Nikolaus, "Prosser's Privacy and the German Right of Personality: are Four Privacy Torts better than one Unitary Concept?", California Law Review, vol. 98, 2010, disponible en: https://scholarship.law.berkeley.edu/cgi/ viewcontent.cgi? article $=2755 \&$ context $=$ facpubs, p. 1944 .

8 Barbas, Samantha, "The Death of the Public Disclosure Tort: A Historical Perspective", Yale Journal of Law and the Humanities, vol. 22, num. 2, 2013, p. 173: "I trace the privacy tort's death to the period between roughly 1920 and 1940, an era that saw the rapid growth and transformation of both old and new media, including newspapers, magazines, radio and motion pictures". La autora explica cómo a raíz de los medios de comunicación se produjo la muerte del public disclosure of private facts. 
precedente legal, que provocó la aprobación de una ley en el estado de Nueva York, en 1903, que prohibía estas situaciones.

Ya en 1905, en el caso Pavest v. New England Life Insurance Co. se encuentran los primeros precedentes donde se defiende el derecho a la privacidad establecido en el artículo de Warren y Brandeis. La foto del artista Pavesich apareció en un anuncio de una compañía de seguros, y fue publicado en el Atlanta Constitution. A pesar de que posó para la instantánea, no dio su consentimiento, por lo que la Corte de Georgia consideró que se había producido una invasión en la privacidad del demandante.

Inmediatamente después de este caso, se produjeron otros similares, en los que se usaba la imagen de personas para anuncios publicitarios sin que mediara el consentimiento oportuno. Y los tribunales fallaron a favor de los afectados, porque consideraron que estos hechos constituían una invasión para la privacidad de los demandantes (véanse en este sentido los siguientes casos: Henry v. Cherry y Webb de 1909; Foster Millburn Co. v. Chinn de 1909; Munden v. Harris de 1911).

Todos estos fallos demuestran la favorable postura que mantuvieron los tribunales estadounidenses durante estos años a favor de la privacidad, gracias al positivo efecto que produjo en el ordenamiento jurídico el artículo de Samuel Warren y Louis Brandeis, donde además de contemplar la intimidad como un derecho fundamental, era prioritario tener en cuenta si el afectado había manifestado el consentimiento oportuno.

También es importante el caso Olmstead v. United States de 1928. Los hechos estaban relacionados con unas escuchas telefónicas que había realizado el gobierno, debido a las sospechas que tenían de que se podían estar incumpliendo algunas leyes en materia de importación, almacenamiento y venta de bebidas alcohólicas. Todos los miembros del tribunal, excepto uno, consideraron que no se había producido violación del derecho a la privacidad.

Pero Brandeis, que en ese momento ya se había convertido en juez de la Corte Suprema, emitió un voto disidente bajo la idea de que el modo en el que se estaba utilizando la tecnología para obtener una prueba constituía una invasión al right to privacy, calificando esta conducta de "dirty business". Incidió en el hecho de que los nuevos avances tecnológicos pueden suponer un peligro para los derechos de la personalidad, denunciando la potencial invasión que sufre la privacidad conforme avanza la tecnología.

Esto es precisamente una visión del desmedro que comenzó a sufrir este derecho dentro del entorno digital. De ahí la necesidad de que al proteger- 
se la intimidad, se tenga en cuenta que para ello en algunas ocasiones se tiene que producir el olvido de ciertas informaciones. ${ }^{9}$

A pesar de que este último caso no es concretamente un antecedente en sentido estricto del derecho al olvido previo a la era digital, se ha considerado importante hacer un repaso de los primeros antecedentes sobre los que tuvieron que pronunciarse los tribunales estadounidenses en materia de privacidad, para poder comprender en profundidad el objeto de estudio del artículo.

En definitiva, desde la publicación del artículo de Warren y Brandeis y durante las dos primeras décadas del siglo XX, en Estados Unidos se empezó a forjar una postura favorable hacia la protección de este derecho, que dio paso a que en los años treinta ya se puedan encontrar los primeros indicios en los que los ciudadanos no solamente reclaman por su privacidad, sino también por el olvido.

\section{De la privacidad al olvido: los cimientos de la actualidad}

Fue Estados Unidos uno de los primeros países en resolver un caso de derecho al olvido anterior a la era digital: Melvin v. Reid en 1931.

Los llamativos hechos comenzaron en 1918, cuando Gabrielle Darley, de profesión prostituta, comenzó una relación amorosa con el deportista Leonard Tropp. Tras un tiempo de noviazgo, ella le dio dinero para que le comprara un anillo de bodas, sin saber que, en realidad, él planeaba casarse con otra mujer, a la que le regaló la mencionada sortija que había comprado con el dinero de Gabrielle. A consecuencia de este hecho, Gabrielle le disparó al deportista en la calle y él murió. En el juicio, ella fue declarada inocente, debido a que convenció al jurado de que el revólver se había disparado accidentalmente. Años más tarde, Adela Rogers, hija de Leonard, escribió una historia, The Red Kimono, contando todos los hechos ocurridos y dando los nombres reales de los protagonistas. Ésta fue llevada al cine en 1927. Como consecuencia, Gabrielle demandó a Adela por invasión de su derecho a la privacidad, ya que ella había rehecho su

9 Zárate Rojas, Sebastián, "La problemática entre el derecho al olvido y la libertad de prensa", Derecom, núm. 13, marzo-mayo, 2013, disponible en: file://D:/DERECHO\%20 AL\%20OLVIDO/ARTÍCULOS/SUDAMÉRICA/CHILE/SEBASTIÁN\%20ZÁRATE\%20 ROJAS.pdf, p. 8: "El derecho al olvido, no consiste en reescribir la historia, sino en impedir que información personal circule y siga siendo procesada". 
vida y clamaba por una segunda oportunidad. La Corte de California consideró que los hechos habían producido una violación en la privacidad de la señora Darley, y que las personas deben tener derecho a olvidar y a ser perdonadas.

Éste se convirtió en uno de los casos más emblemáticos de Estados Unidos, ya que se puede considerar que es un reconocimiento judicial del derecho al olvido, del derecho a tener una segunda oportunidad, donde se pueden olvidar los hechos del pasado cuando ya no tienen relevancia para la conformación de la opinión pública del presente..$^{10}$

En este caso comienzan a establecerse los orígenes del derecho al olvido previos a la era digital: ciudadanos que quieren volver a recuperar su privacidad, pero siempre guardando el delicado equilibrio que es necesario mantener entre este derecho y el derecho a la información. Tal como explica Meg Leta Jones: "After Melvin, the rehabilitive function of privacy began to dwindle, and the definition of newsworthiness began to grow". ${ }^{11}$

Éste fue precisamente el primer supuesto claro que se puede encontrar en Estados Unidos relativo al derecho al olvido previo a la era digital. De hecho, es el caso que sirvió para ejemplificar una de las teorías más consolidadas relativas a la privacidad. La teoría de los cuatro torts que William Prosser consiguió plasmar en su célebre trabajo "Privacy", ${ }^{12}$ y que marcó un antes y un después, ya que ayudó a complejizar el concepto acuñado setenta años atrás por Warren y Brandeis.

Concretamente, el segundo de los cuatro torts, relativo a la revelación de hechos privados, parte para su explicación del caso Melvin v. Reid.

La importancia de este fallo radica en que de su argumentación se desprende una postura favorable hacia el derecho al olvido, como un derecho relacionado con la privacidad, y que pertenece al ámbito de los derechos fundamentales de los ciudadanos. Una visión muy certera y que permite guardar un equilibrio entre información e intimidad, teniendo en cuenta

10 Friedman, Laurence, Guarding Life's Dark Secrets: Legal and Social Controls over Reputation, Propriety, and Privacy, California, Standford University Press, 2007.

11 Jones, Meg Leta, Crtl Z The Right to be Forgotten, Nueva York, NYU Press, 2016, p. 59.

12 Prosser, William, "Privacy", California Law Review, vol. 48, num. 3, 1960, disponible en: https://doi.org/10.3145/epi.2017.mar.17, p. 389: "These four torts may be describe as follows: 1. Intrusion upon the plaintiff's seclusion or solitude, or into his private affairs. 2. Public disclosure of embarrassing private facts about the plaintiff. 3 . Publicity which places the plaintiff in a false light in the public eye. 4. Appropiation, for the defendant's advantage, of the plaintiff's name or likeness". 
en cada caso sus particularidades para poder establecer hacia dónde debe inclinarse la balanza.

Sin embargo, durante las décadas posteriores, tal como se va a analizar a continuación, la jurisprudencia y la doctrina cambiaron de rumbo hasta consolidar la actual visión que existe en Estados Unidos, y que se ha extendido a los principales países cuyo sistema jurídico está basado en el common law, dando una prioridad, casi absoluta, al derecho a la información, ${ }^{13}$ a pesar de que es defendido entre los constitucionalistas que no hay ningún derecho que deba ser absoluto. ${ }^{14}$

\section{La figura pública involuntaria: un antes y un después para el derecho al olvido}

Esta tendencia fue revertida en el caso Time Inc. v. Hill de 1967, en el que se comenzó a hablar de las figuras públicas involuntarias.

La familia Hill fue secuestrada en su casa en 1952 por tres criminales convictos. A raíz de estos hechos, el matrimonio y sus cinco hijos se mudaron de Pennsylvania, con objeto de poder volver a tener una vida de anonimato. La revista Time publicó un reportaje sobre el caso, debido a que también se había creado una obra de teatro en Broadway con el nombre The Desperate Hours, adaptación del libro escrito por Joseph Haye. La Corte Suprema entendió que no había violación en la privacidad de la familia Hill, sentando el criterio jurisprudencial de la figura pública involuntaria por su implicación en hechos noticiosos, y provocando que no haya olvido para ninguna persona sin importar la situación.

$\mathrm{Y}$ es que, tal como afirma Ignacio Covarrubias, el tribunal supremo añadió un nuevo argumento constitucional sobre la prevalencia de la libertad de expresión respecto del derecho a la intimidad, al expresar que la primera enmienda ya no estaba destinada a proteger únicamente la expresión política o el comentario de los asuntos públicos, sino también la información noticiosa. ${ }^{15}$

13 Moreno Bobadilla, Ángela, "El derecho al olvido digital: una brecha entre Europa y Estados Unidos", Revista de Comunicación, vol. 18, núm. 1, 2019, disponible en: https://doi.org/10.26441/RC18.1-2019-A13, p. 267.

14 Gómez Sánchez, Yolanda, Constitucionalismo multinivel. Derechos fundamentales, Sanz y Torres, 2011, pp. 55 y ss.

15 Covarrubias Cuevas, Ignacio, La vida privada de las figuras públicas. El interés público como argumento que legitima la intromisión en la vida privada, Santiago de 
Esta jurisprudencia ha sido corroborada en casos posteriores, como el de Briscoe v. Reader's Digest Assoc. de 1971, en los que los tribunales consideraron que un personaje público no se vuelve a convertir en persona privada por el mero transcurso del paso del tiempo. En este caso, el máximo tribunal del país revirtió una sentencia de la Corte de Apelaciones de California, en la que había dado la razón al señor Briscoe, que demandó a la revista Reader's Digest por publicar un reportaje sobre su pasado criminal. Pero la Corte Suprema confirmó el criterio de que una persona que se ha convertido en pública nunca más vuelve a ser privada.

Estos casos ejemplifican una postura contraria a lo defendido en el artículo de Warren y Brandeis, y a la tendencia de los tribunales durante las primeras décadas del siglo XX. Desafortunadamente, la privacidad y el olvido pierden peso frente a la información, al verlos como derechos antagónicos entre sí, cuando en realidad son dos derechos complementarios en cualquier sistema democrático: los ciudadanos necesitan información para desarrollar sus obligaciones para con el sistema democrático, y también necesitan privacidad para su vida cotidiana, porque hay ciertos asuntos que no son información, sino mero morbo o sensacionalismo.

\section{Estados Unidos: ni olvido ni perdón}

A pesar de ser uno de los primeros países en dictar una sentencia que reconoce el derecho a las segundas oportunidades, la jurisprudencia cambió de rumbo, y asentó dos criterios que impiden que en la actualidad se pueda configurar un derecho al olvido digital: una noticia de interés público siempre lo será, con independencia del tiempo transcurrido, y una persona que se convierte en pública (con independencia de las circunstancias) nunca más vuelve a ser privada. ${ }^{16}$

Y es que el país donde radica Silicon Valley encuentra que la configuración de un derecho de estas características podría suponer una violación de la primera enmienda constitucional, donde se recoge la libertad de prensa

Chile, Thomson-Reuters, 2013, p. 270: "Con este avance en perjuicio de la intimidad, el Tribunal otorga escudo constitucional a la prensa para reportear la vida de personas privadas involucradas involuntariamente en hechos noticiosos".

16 Abril, Patricia y Pizarro, Eugenio, "La intimidad europea frente a la privacidad americana. Una visión comparativa del derecho al olvido", Indret. Revista para el Análisis del Derecho, núm. 1, 2014, disponible en: http://www.indret.com/pdf/1031.pdf, pp. 21 y ss. 
y de expresión, y que además proscribe expresamente que el Congreso pueda adoptar cualquier ley que limite la libertad de expresión.

Aunque en realidad la cuestión del derecho al olvido no es del todo ajena para Estados Unidos, desde que en enero de 2015 se publicara en California una ley, California Senate Bill 568 2013, que permite a todos los menores de dieciocho años borrar (que no desindexar, sino borrar de forma permanente) toda la información que ellos mismos hayan subido a las redes sociales. Es decir, se está reconociendo the right to erase para un colectivo en concreto.

Pero esta situación, al menos hasta la fecha, todavía no es extrapolable al ámbito de los medios de comunicación on line, que seguirá mostrándose desfavorable a cualquier forma de manifestación del derecho al olvido.

\section{LA PRIMACÍA DE LA PRIVACIDAD EN EUROPA}

El viejo continente se ha erigido en la actualidad como el firme defensor del derecho al olvido digital, y es que, tal como afirma Meg Leta Jones, "Europe has a long history of privacy regulation, much of which is relevant to the right to be forgotten". ${ }^{17}$

Esta postura asentada en Europa permite guardar el equilibrio entre información y privacidad, gracias a que desde hace varias décadas la evolución jurisprudencial se ha mantenido firme y estable, y se ha adaptado a los nuevos cambios sociales que se han implementado, pero con una clara línea jurisprudencial: cuando la información carece de interés público, debe prevalecer la intimidad.

Por ello, en los países continentales de tradición románica, principalmente en Francia, antes de la creación de Internet ya se pueden encontrar los primeros antecedentes en esta materia.

\section{Los sistemas civilistas de influencia francesa:}

la cuna de la innovación jurídica

Ya en la segunda mitad del siglo XVIII, incluso antes de la publicación del artículo de Warren y Brandeis, existe jurisprudencia que empezó a reconocer el derecho a la privacidad.

17 Jones, Meg Leta, op. cit., nota 12, p. 27.

Esta obra está bajo una Licencia Creative Commons Atribución-NoComercial-SinDerivar 4.0 Internacional, IIJ-UNAM. 
En 1867, Alejandro Dumas, autor de Los tres mosqueteros, reclamó por unas fotografías que se habían publicado sobre él. A pesar de que dio su consentimiento inicial, posteriormente lo retiró. La Corte francesa le dio la razón, porque encontró que cuando el consentimiento es retirado, hay una intrusión a la privacidad. Como se puede comprobar a través de este prematuro caso, Francia se convirtió desde hace más de dos siglos en uno de los países precursores del derecho a la intimidad, ${ }^{18}$ donde uno de sus principales elementos, cuando la información no tiene interés público, es el consentimiento de la persona afectada.

A esto hay que añadir una ley de 1868 , Loi relative à la presse, en la que se prohibía la publicación de hechos relativos a la vida privada de las personas, excepto que esa información ya fuera pública o hubiera mediado el consentimiento oportuno.

Otro de los primeros antecedentes en materia de olvido previo a la era digital se encuentra en Quebec, Canadá, donde el derecho privado sigue la tradición civilista, mientras que el derecho público, la del common law.

Concretamente, es el caso Goyette c. Rodier, que se remonta a 1889, y que está basado en el principio de responsabilidad por culpa. ${ }^{19}$ Los hechos se relacionan con una información que publicó un diario local de la época, y que provocó que una persona anónima que había sido objeto de ciertas acusaciones en el pasado volviera a convertirse en persona pública. El tribunal canadiense dictaminó que los hechos que han sido de interés público en el pasado, pero que ya no tienen relevancia en el presente, pueden ocasionar un daño en la vida privada de las personas, y que por lo tanto, ya no deben ser considerados como noticiosos, debido a que han perdido su actualidad.

Esta sentencia siembra un verdadero precedente en materia de olvido para todos los países de tradición jurídica civilista, al establecer que cuando una información, relacionada con una persona privada, vuelve a publicarse nuevamente ante la opinión pública, se está impidiendo que sus protagonistas puedan tener derecho a una segunda oportunidad. Es

\footnotetext{
18 Ost, François, El tiempo del derecho, México, Siglo XXI Editores, 2005.

19 Simón Castellano, Pere, El reconocimiento del derecho al olvido digital en España y en la UE, Barcelona, Bosch, 2015, p. 107: "En cualquier caso, se observa como la doctrina y la jurisprudencia francesa y del Quebec, han entendido que el derecho general al olvido comporta también un deber de olvidar por parte de los demás, que se concreta más exactamente en un deber de no divulgar hechos pasados que puedan condicionar el futuro de las personas".
} 
importante resaltar en este punto, que esto dice relación con que el interés público de una información no es perpetuo, porque en caso contrario el derecho a la intimidad siempre se vería perjudicado, impidiendo que se cumpla un principio básico del derecho penal, como es la reinserción social de los individuos.

\section{La jurisprudencia francesa como ejemplo para el continente}

Entre los años sesenta y ochenta los tribunales franceses dictaron varias sentencias relativas a esta materia, mediante las que se posicionaron como un firme defensor de las segundas oportunidades.

Un ejemplo es la sentencia del Tribunal de Gran Instancia de Sena, del 4 de octubre de 1965, pionera al reconocer el derecho de los ciudadanos a tener una segunda oportunidad. Resolvió una demanda de una de las amantes del famoso asesino en serie Henri Landru, porque su relación sentimental fue representada en una película muchos años después de que el noviazgo hubiera finalizado. A pesar de que finalmente el órgano jurisdiccional francés rechazó la demanda, ya que la actora había publicitado su relación con el señor Landru, se comienza a hablar del droit a l'oublie, sembrándose los orígenes europeos del derecho al olvido previo a la era digital.

El mismo criterio se utilizó frente a la publicación de la autobiografía del famoso delincuente Mesrine, cuya expareja reclamaba que el libro perjudicaba su reinserción social. Este caso se puede ver en la sentencia del Tribunal de Gran Instancia de París, del 6 de diciembre de 1979.

Otro ejemplo es el caso Mme. M. c. Filipacchi et Cogedipresse, de 1983, que también defendió que las personas privadas que se hayan visto involucradas en acontecimientos públicos pueden reivindicar el derecho al olvido cuando la información ya no tenga interés para la conformación de la opinión pública. Esto debido a que el recuerdo de esos acontecimientos, cuando no esté fundado en necesidades históricas o si su naturaleza es tal que puede herir su sensibilidad, no se puede considerar legítimo.

Todos éstos, son tan sólo algunos de los ejemplos de la importante y sólida jurisprudencia que se sentó en Francia relativa al olvido en el caso de informaciones protagonizadas por personas privadas, que se han convertido en irrelevantes debido al paso del tiempo, por lo que sus protagonistas tienen derecho a volver a comenzar, jurisprudencia acorde con el ideal de 
dignidad y del libre desarrollo de la personalidad del que nacen todos los derechos de la personalidad.

\section{La intimidad como pilar fundamental de los sistemas europeos}

El gran desarrollo jurisprudencial que ha tenido esta materia en Francia, y por influencia en la mayor parte de los países de la Europa continental, ha propiciado el importante desarrollo que tiene el derecho al olvido en la actualidad. ${ }^{20} \mathrm{Y}$ en todos los Estados existe un pilar común: su derivación del derecho a la intimidad, así como de la protección de datos personales. ${ }^{21}$

El punto de inflexión en Europa se produjo en 2014 con la sentencia del caso Costeja, dictada por el TJUE 22 (comúnmente conocido como Tribunal de Luxemburgo), que no hace sino consolidar el derecho al olvido europeo y fomentar su oposición dentro de uno de los principales exponentes del common law. Mientras que en el viejo continente se empieza a considerar que los motores de búsqueda, dígase Google, Yahoo o Bing, entre otros, son responsables por el tratamiento de datos, el país donde radica Silicon Valley se alza contra esta postura.

El señor Costeja, reputado empresario catalán, había sido protagonista de una noticia en el periódico español de La Vanguardia, porque figuraba en un anuncio de una subasta de inmuebles relacionada con un embargo de deudas a la seguridad social. Estos hechos habían tenido lugar mientras desarrollaba sus actividades empresariales, en las que dejó de pagar las cuotas a la seguridad social, que tuvieron como consecuencia el menciona-

20 Trudel, Pierre, "L' oubli en tant que droit et obligation dan les systèmes juridiques civilistes", Faculté de droit, Université de Montréal, 2013, pp. 1-5.

21 Corral Talciani, Hernán, "El derecho al olvido en Internet: antecedentes y bases para su configuración jurídica", Revista Jurídica Digital UANDES, núm. 1, 2017, disponible en: http://rjd.uandes.cl/index.php/rjduandes/article/view/7/39, p. 57: "A nuestro entender el derecho al olvido está en proceso de configuración como un derecho de la personalidad. Como es sabido, la protección de bienes extrapatrimoniales de la persona se inició en la doctrina alemana por medio del llamado Derecho General de la Personalidad que se planteaba como un único derecho que podía adaptarse para hacer frente a las diversas agresiones que podía sufrir el individuo humano en el ámbito no patrimonial”. Cotino Hueso, Lorenzo, "Google y el derecho al olvido en Europa. Algunos «olvidos» y otras tendencias negativas respecto de las libertades informativas en Internet", en Labrador, María José y Carter, Edward (coords.), Google: derecho al olvido y desafíos éticos en el escenario mediático digital, Santiago, Ril Editorial, 2018, pp. 129-168.

22 Tribunal de Justicia de la Unión Europea. 
do embargo. El hecho de que cada vez que se introducía su nombre y apellidos en un buscador apareciera la mencionada información, le impedían que tuviera una segunda oportunidad. Además, argumentaba que la noticia ya no tenía interés público en la actualidad, y solicitaba que ésta no fuera accesible cuando su nombre se escribía en un buscador.

El litigio se basaba en saber si Google estaba obligada a borrar de Internet todos los datos personales de la noticia, y que se recuperaban a través del motor de búsqueda. Dicha información pertenecía al pasado de la vida privada del ciudadano.

El tribunal determinó que los ciudadanos pueden solicitar la eliminación de datos personales contenidos en la Red cuando su tratamiento sea ilegítimo, o sea, que no sea adecuado, pertinente o excesivo en relación con los fines y el tiempo transcurrido. Por lo tanto, se pronunció a favor del ciudadano, y exigió la desindexación de la información tanto de Google Inc como de Google Spain. ${ }^{23}$

No obstante, la información sigue accesible en el universo virtual cuando ésta se busca a través de parámetros diferentes del nombre del señor Costeja, no implicando que la información quede suprimida de la fuente original. La única consecuencia práctica es que el dato (o información no deseada) quede desvinculado del nombre concreto cuando se realiza una búsqueda. Esto, para guardar un equilibrio entre el derecho al olvido y el derecho a la información, tal como manifiesta el tribunal de Luxemburgo en la sentencia aludida.

En la actualidad, a raíz de la entrada en vigor del Reglamento (UE) 2016/679 del Parlamento Europeo y del Consejo, del 27 de abril de 2016, relativo a la protección de las personas físicas en lo que respecta al tratamiento de datos personales y a la libre circulación de éstos, que es aplicable desde el 25 de mayo de 2018, y en cuyo artículo 17 se recoge de forma expresa el derecho al olvido como un derecho de cancelación, los ciudadanos europeos tienen la oportunidad de solicitar ante los respectivos órganos de sus países nacionales que se produzca la desindexación de informaciones que aparecen en los buscadores cuando se introduce su nombre. ${ }^{24}$

23 Rallo Lombarte, Artemi, El derecho al olvido en internet. Google versus España, Madrid, Centro de Estudios Políticos y Constitucionales, 2014. El exdirector de la AEPD hace un exhaustivo análisis de esta sentencia.

24 Martínez-Martínez, Dolores Fuensanta, "Unificación de la protección de datos 
Todo gracias al prematuro desarrollo jurisprudencial que hubo sobre esta materia en los países europeos, que han construido una sólida doctrina en torno a la protección de la privacidad de los ciudadanos en el entorno digital, cuyos orígenes se remontan a la era previa de la creación de Internet.

\section{CONCLUSIONES}

Fue mucho antes de la revolución tecnológica cuando las personas comenzaron a reclamar tanto por su privacidad como por su derecho a volver a comenzar.

Esta necesidad de perdón y rendición se denominó "derecho al olvido" y se sentó como criterio jurisprudencial tanto en Estados Unidos como en Francia, lo que contribuyó a conformar los orígenes del emergente derecho tan debatido en la actualidad.

Todos los casos analizados cuentan con un pilar común: personas privadas, que debido a diversas circunstancias ajenas a su voluntad se han convertido en públicas. Como consecuencia, solicitan que las mencionadas informaciones desaparezcan del radar de la opinión pública, bajo el argumento de que el transcurso del tiempo las ha convertido en irrelevantes.

Ante una misma situación, las decisiones jurisprudenciales varían de forma considerable. En Estados Unidos, a pesar de que se comenzó a aceptar esta posibilidad, desde los años treinta la jurisprudencia se posiciona firmemente en contra, al establecer que las noticias públicas, así como sus protagonistas, nunca más vuelven a ser privadas.

Sin embargo, en Francia se asienta el criterio opuesto. Cuando la información ya no es actual, deja de ser considerada como susceptible de protegerse bajo el criterio del interés público, por lo que sus protagonistas tienen derecho a reclamar su derecho al olvido.

Estos dos países sirvieron de ejemplo para que en cada uno de sus respectivos sistemas jurídicos se asentaran dos visiones contrapuestas de una misma cuestión, sembrando los orígenes de dos visiones antagónicas respecto del derecho al olvido: en Estados Unidos se considera que vulnera la libertad de expresión, mientras que en Europa se ha construido como un derecho derivado de la privacidad y de la protección de datos personales.

personales en la Unión Europea: desafíos e implicaciones", El Profesional de la Información, vol. 27, núm. 1, enero-febrero, 2018, disponible en: https://doi.org/10.3145/ epi.2018.ene.17, pp. 185-194. 


\section{BIBLIOGRAFÍA}

ABril, Patricia y PiZARro, Eugenio, "La intimidad europea frente a la privacidad americana. Una visión comparativa del derecho al olvido", Indret: Revista para el Análisis del Derecho, núm. 1, 2014, disponible en: $h t t p: / / w w w . i n d r e t . c o m / p d f / 1031 . p d f$.

Álvarez CARo, María, Derecho al olvido en internet: el nuevo paradigma de la privacidad en la era digital, Madrid, Reus, 2015.

BARBAS, Samantha, "The Death of the Public Disclosure Tort: a Historical Perspective", Yale Journal of Law and the Humanities, vol. 22, núm. 2, 2013.

CORRAL TALCIANI, Hernán, "El derecho al olvido en Internet: antecedentes y bases para su configuración jurídica", Revista Jurídica Digital UANDES, num. 1, 2017, disponible en: http://rjd.uandes.cl/index.php/ rjduandes/article/view/7/39.

Cotino Hueso, Lorenzo, "Google y el derecho al olvido en Europa. Algunos «olvidos», y otras tendencias negativas respecto de las libertades informativas en Internet", en LABRADOR, María José y CARTER, Edward (coords.), Google: derecho al olvido y desafíos éticos en el escenario mediático digital, Santiago, Ril Editorial, 2018.

CovarRubias Cuevas, Ignacio, La vida privada de las figuras públicas. El interés público como argumento que legitima la intromisión en la vida privada, Santiago, Thomson-Reuters, 2013.

De Terwagne, Cecile, "Privacidad en Internet y el derecho a ser olvido/ al olvido", Revista de Internet, Derecho y Política, núm. 13, febrero de 2012, disponible en: http://doi.org/10.7238/idp.v0i13.1400.

FRIEDMAN, Laurence, Guarding Life's Dark Secrets: Legal and Social Controls over Reputation, Propiety, and Privacy, California, Standford University Press, 2007.

GómEz SÁnCHEZ, Yolanda, Constitucionalismo multinivel. Derechos fundamentales, Sanz y Torres, 2011.

GonZÁlez Fuster, Gloria, The Emergence of Personal Data Protection as a Fundamental Right of the EU, Suiza, Springer, 2014.

JONES, Meg Leta, Crtl Z The right to be forgotten, Nueva York, NYU Press, 2016. 
MARTÍNEZ- MARTÍNEZ, Dolores Fuensanta, "Unificación de la protección de datos personales en la Unión Europea: desafíos e implicaciones", El Profesional de la Información, vol. 27, núm. 1, enero-febrero de 2018, https://doi.org/10.3145/epi.2018.ene.17.

MAYER- SchÖNBERGER, Viktor, Delete. The Virtue of Forgetting in the Digital Age, Princeton, Princeton University Press, 2009.

Moreno BobAdilla, Ángela, "El derecho al olvido digital: una brecha entre Europa y Estados Unidos", Revista de Comunicación, vol. 18, núm. 1, 2019, disponible en: https://doi.org/10.26441/RC18.1-2019-A13.

Moreno Bobadilla, Ángela, Intimidad y menores, Madrid, Centro de Estudios Políticos y Constitucionales, 2017.

OST, François, El tiempo del derecho, México, Siglo XXI Editores, 2005.

Prosser, William, "Privacy", California Law Review, vol. 48, núm. 3, 1960.

Rallo LOMBARTE, Artemi, "Del derecho a la protección de datos a la garantía de nuevos derechos digitales", en RALlo LOMBARTE, Artemi (dir.), Tratado de protección de datos. Actualizado con la Ley Orgánica $3 / 2018$, de 5 de diciembre, de protección de datos personales y garantía de los derechos digitales, Valencia, Tirant lo Blanch, 2019.

RAllo LOMBARTE, Artemi, El derecho al olvido en Internet. Google versus España, Madrid, Centro de Estudios Políticos y Constitucionales, 2014.

SANTín, Marina, "La problemática del derecho al olvido desde la perspectiva histórica de la autorregulación periodística", El Profesional de la Información, marzo-abril, vol. 26, núm. 2, 2017, disponible en: https:// doi.org/10.3145/epi.2017.mar.17.

Schwartz, Paul M. y Piefer, Karl-Nikolaus, "Prosser's Privacy and the German Rright of Personality: are four Privacy Torts better than one Unitary Concept?", California Law Review, vol. 98, 2010, disponible en: https://scholarship.law.berkeley.edu/cgi/viewcontent.cgi? article =2 $755 \&$ context $=$ facpubs.

Simón CAStellano, Pere, El reconocimiento del derecho al olvido digital en España y en la UE, Barcelona, Bosch, 2015.

Simón CASTELlanO, Pere, "El carácter relativo del derecho al olvido en la red y su relación con otros derechos, garantías e intereses legítimos", en Corredoira y Alfonso, Loreto y Cotino Hueso, Lorenzo (dirs.), Libertad 
de expresión e información en Internet. Amenazas y protección de los derechos personales, Madrid, Centro de Estudios Políticos y Constitucionales, 2013.

TRUDEL, Pierre, "L' oubli en tant que droit et obligation dan les systèmes juridiques civilistes", Faculté de droit, Université de Montréal, 2013.

WARren, Samuel y BrandeIs, Louis, "The Right to Privacy", Harvard Law Review, vol. 4, núm. 5, 1890.

Werro, Franz, "The Right to Inform v. the Right to be Forgotten: a Transatlantic Clash", Georgetown University. Center for Transnational Legal Studies Colloquium, núm. 2, 2009.

Whitman, James Q., “The Two Western Cultures of Privacy: Dignity Versus Liberty", Yale Law Journal, vol. 113, 2017, disponible en: file:///D:/ DERECHO\%20AL\%20OLVIDO/UF/OLVIDO\%20Y\%20PRIVACIDAD/ARTÍCULOS/WHITMAN.pdf.

ZÁRATE RoJAS, Sebastián, "La problemática entre el derecho al olvido y la libertad de prensa", Derecom, núm. 13, marzo-mayo, disponible en: file://D:/DERECHO\%20AL\%20OLVIDO/ARTÍCULOS/SUDAMÉRI CA/CHILE/SEBASTIÁN\%20ZÁRATE\%20ROJAS.pdf.

Fecha de recepción: 29 de abril de 2020.

Fecha de aceptación: 20 de abril de 2020.

Esta obra está bajo una Licencia Creative Commons Atribución-NoComercial-SinDerivar 4.0 Internacional, IIJ-UNAM. 